\title{
The Challenges of Adverse Drug Reaction Evaluation
}

\section{Karine Balero Marante*}

Regional Pharmacovigilance Manager, Drugs for Neglected Diseases Initiative, Brazil

\begin{abstract}
Prevention of adverse drug reactions (ADRs) is the essence of Pharmacovigilance and its precise diagnosis is crucially a primary step, which still remains a challenge among specialists. The objective here is to investigate and offer a notion of commonly used and the developed methods of causality assessment tools for the diagnosis of ADRs and discuss their pros and cons. There are several recognized ways for assessment methods with decisive factors of causality evaluation, all the information regarding reasons allocating causality, the advantages and limitations of the appraisal methods were extracted and evaluated. Expert judgment is typically based on the decisive factor on which algorithms are based, nevertheless in imprecise manner. The probabilistic methods use the similar principle; however, connect probabilities to each measure. Such approaches are quite skeptical and liable to generate cloudy causation results. The final evaluation is quite intricate due to numerous inherent shortcomings in causality assessment tools. Thus we are still looking for developing a high quality assessment tool (very specific, but at the same time, sensitive enough) which can meticulously establish suitable diagnostic criteria for ADRs with universal acceptance to improvise the fundamental aspect of drug safety.
\end{abstract}

Keywords: Adverse drug reactions; Pharmacovigilance; Drug safety; Febrile neutropenia

\section{Abbreviations: ADR: Adverse drug reactions \\ Introduction}

The most important problem in evaluating Adverse Drug Reactions (ADRs) is to determine the causal relationship between the drug and undesirable clinical events. Several evaluation methods (algorithms) were and are published in order to reduce the variability in the evaluation and to maintain a uniformity/standard. But even with algorithms, many Institutions and companies end up using the Global Introspection (Clinical Judgement) method as algorithms are still limited for evaluations of events occurring during clinical trials and for spontaneous events with little information available.

\section{Methods}

Checking the timeliness between reaction onset and drug use, compatibility between the nature of the event and drug pharmacology (including knowledge of the nature and frequency of ADR), medical or pharmacological plausibility (signals and symptoms, laboratory tests and mechanism of action) are key points for a causality assessment. In addition to this, it is also important to verify the possibility or exclusion of other causes for the observed event. The causality assessment consists of the assessment of the likelihood that an adverse event is a consequence of the use of the drug when it refers to an individual case [1-10].

The categories of causality are:

\section{Related}

There is a reasonable causal relationship between suspect product and adverse event. The event responds to withdrawal of the suspected drug (Discontinuation of administration: Positive dechallenge) and reappears with re-introduction, when clinically feasible (positive rechallenge).

\section{Probable (Likely)}

There is a reasonable causal relationship between the suspect product and the adverse event. The event responds to the interruption of administration (positive dechallenge). Reintroduction is not required (rechallenge is N/A).

\section{Possible}

There is a reasonable causal relationship between the suspected product and the adverse event. Information about discontinuation of administration is absent or unclear (dechallenge UNK or N/A).

\section{Unlikely}

There is a chronological relationship with the administration of the suspect product, but there is no reasonable causal relationship between the suspected drug and the adverse event.

\section{Unrelated}

There is no chronological relationship with the administration of the suspect product (too premature, too late, or the suspect product was not administered), or there is a reasonable causal relationship between an agent other than the suspected drug, concomitant disease or circumstance and the adverse event (AE).

According to WHO, there are still 2 more types of causality categories (which are not applicable for clinical research):

Conditional/Unclassified: More data is needed for proper assessment or when additional data is being analyzed.

Non-accessible/Unclassifiable: Notification that suggests an adverse event that cannot be evaluated because the information is insufficient or contradictory and cannot be completed or verified.

Important: For clinical research and in some countries, for (Figure 1) spontaneous reports as well, causality can be classified only as

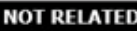

${ }^{*}$ Corresponding author: Karine Balero Marante, Regional Pharmacovigilance Manager, Drugs for Neglected Diseases initiative, Brazil, Tel: +55 212529 0400; E-mail: kbalero@dndi.org

Received: April 17, 2018; Accepted May 03, 2018; Published May 10, 2018

Citation: Marante KB (2018) The Challenges of Adverse Drug Reaction Evaluation. J Pharmacovigil 6: 260. doi:10.4172/2329-6887.1000260

Copyright: (c) 2018 Marante KB. This is an open-access article distributed under the terms of the Creative Commons Attribution License, which permits unrestricted use, distribution, and reproduction in any medium, provided the original author and source are credited. 


\section{"RELATED” or "NOT RELATED”.}

The need to formulate questions that help and at the same time unify the diagnostic criteria of ADR has given rise to several algorithms and decision tables that, when properly applied, allow greater security in the establishment of the causal relation.

They emerged from the 1970s and became more or less accepted according to their applicability in clinical routine, reproducibility and ease of interpretation.

Among the great variety of existing algorithms and scales of evaluation of causality, the most known are: Algorithm of Karch and Lasagna, Scale of Kramer, Algorithm of Naranjo, Algorithm of Begaud, Algorithm of Jones, among others.

The Karch and Lasagna's Algorithm: It arose in 1977 and consists in three tables with a number of closed questions to be answered dichotomously (The combination of results leads to establish the causal relationship). According to established criteria, the reaction is classified as related, probable, possible, conditional or unrelated and we can also identify: atypical prescription compliance, prescription error, drugdrug interaction, terminal illness, appropriate use of the drug.

The Kramer's Scale: It emerged in the late 1970s. It uses the same criteria of Karch and Lasagna Algorithm, but also it's possible to check "drug level and evidence of over dosage". (It consists in 56 questions).

The Naranjo's Algorithm: It was developed in 1981 to establish a simpler method for the non-specialists use. The authors created a probability scale with 10 questions with "Yes or No" answers, based on the traditional criteria for evaluating adverse reactions. The sum of the (Table 1) values assigned to each of the items allows establishing the causal relationship and classifying the adverse reactions. This systematic method offers a sensitive way to monitor ADRs and may be applicable to postmarketing drug surveillance.

The Begaud's Algorithm: This is a French criterion, with threestage process: assessment of 3 chronological criteria (challenge, dechallenge and rechallenge); assessment of clinical and biological findings; combination of chronological and (Tables 2 and 3) symptomatological assessments to obtain a 3-degree global score (1: doubtful, 2: possible, 3: probable). It involves clinical criteria and the chronology of events, is simple to apply and does not require specific knowledge of the pharmacology of the involved drug.

The Jones's Algorithm: This consists in "Yes-No" series, with no score (Figure 2) calculation. It uses the same criteria of the Begaud algorithm, plus the evaluation of results of the interruption and reintroduction of the suspected drug (dechallenge and rechallenge). The method of global introspection (Clinical judgment), is widely used by Companies and Institutions for being more subjective, detailed and possible to be conclusive, even with few information available. To use this method, it (Figures 3 and 4) is important that the evaluator: has knowledge of the pharmacology and prior knowledge of adverse events (AEs), associates (time and place) of AEs and drugs, analyzes plausibility (medical/biological) and the probability or exclusion of other causes.

\section{Results}

When analysing each method individually, it is possible to identify some limitations:

\section{The Karch and Lasagna's Algorithm}

Only allows an ADR to be judged/defined if there is re-exposure to the drug (rechallenge) which rarely occurs. And while it allows

\begin{tabular}{|c|c|c|c|c|}
\hline Question & Yes & No & Do not know & Score \\
\hline 1. Are there previous conclusive reports on this reaction? & +1 & 0 & 0 & - \\
\hline 2. Did the adverse event appear after the suspected drug was administered? & +2 & -1 & 0 & - \\
\hline $\begin{array}{l}\text { 3. Did the adverse event improve when the drug was discontinued or a specific antagonist was } \\
\text { administered? }\end{array}$ & +1 & 0 & 0 & - \\
\hline 4. Did the adverse event reappear when the drug was readministered? & +2 & -1 & 0 & - \\
\hline 5. Are there alternative causes that could on their own have caused the reaction? & -1 & +2 & 0 & - \\
\hline 6. Did the reaction reappear when a placebo was given? & -1 & +1 & 0 & - \\
\hline 7. Was the drug detected in blood or other fluids in concentrations known to be toxic? & +1 & 0 & 0 & - \\
\hline $\begin{array}{l}\text { 8. Was the reaction more severe when the dose was increased or less severe when the dose was } \\
\text { decreased? }\end{array}$ & +1 & 0 & 0 & - \\
\hline 9. Did the patient have a similar reaction to the same or similar drugs in any previous exposure? & +1 & 0 & 0 & - \\
\hline 10. Was the adverse event confirmed by any objective evidence? & +1 & 0 & 0 & - \\
\hline & & & \multicolumn{2}{|c|}{$\begin{array}{l}\text { Total Score: define>8; probable 5-8; } \\
\text { possible 1-4; doubtful } 0\end{array}$} \\
\hline
\end{tabular}

Table 1: Adverse Drug Reaction Probability Scale.

\begin{tabular}{|c|c|c|}
\hline Method & Advantages & Limitations \\
\hline Karch \& Lasagna's Algorithm & $\begin{array}{l}\text { No specific advantage in comparison with any } \\
\text { other methods }\end{array}$ & Reliability and validity not well established \\
\hline Kramer's Scale & $\begin{array}{l}\text { No specific advantage in comparison with any } \\
\text { other methods }\end{array}$ & $\begin{array}{c}\text { Employ exhaustive flowcharts, excessively intricate and protracted for realistic } \\
\text { application }\end{array}$ \\
\hline Naranjo's Algorithm & Simple and brief most extensively used & Dependability and validity not confirmed in children \\
\hline Begaud's Algorithm & $\begin{array}{l}\text { No specific advantage in comparison with any } \\
\text { other methods }\end{array}$ & $\begin{array}{c}\text { Its application requires } 3 \text {-stage flow chart, not protracted but unable to employ all } \\
\text { feature characteristically utilized in ADR appraisal }\end{array}$ \\
\hline Jones's Algorithm & $\begin{array}{c}\begin{array}{c}\text { Shorter and quicker to complete and detect the } \\
\text { least ADR }\end{array}\end{array}$ & Cannot identified actual cause \\
\hline Global Introspection & $\begin{array}{l}\text { Most common approach: major role in the } \\
\text { identification and rating of potential ADRs; more } \\
\text { sensitive }\end{array}$ & $\begin{array}{l}\text { Inter- and intra-rater contradiction; subjectivity \& imprecision; poor reproducibility } \\
\text { because it is mainly based on expert clinical judgements. }\end{array}$ \\
\hline
\end{tabular}

Table 2: Advantages and limitations of causality assessment tools. 


\begin{tabular}{|c|c|c|}
\hline Methods & PROS & CONS \\
\hline $\begin{array}{c}\text { Global introspection: Clinical judgement, an expert } \\
\text { panel considering all available data relevant to a } \\
\text { suspected ADR. }\end{array}$ & $\begin{array}{c}\text { Most common approach: major role in the identification } \\
\text { and rating of potential ADRs; more sensitive. }\end{array}$ & $\begin{array}{c}\text { Inter- and intra-rater contradiction; subjectivity \& } \\
\text { imprecision; poor reproducibility because it is mainly } \\
\text { based on expert clinical judgements. }\end{array}$ \\
\hline $\begin{array}{c}\text { Algorithms: Sets of specific questions with associated } \\
\text { scores for calculating the likelihood of cause-effect } \\
\text { relationship; }\end{array}$ & $\begin{array}{c}\text { More reliable and reproducible measurement (least } \\
\text { inter- and intra-rater contradiction); simplicity. }\end{array}$ & $\begin{array}{c}\text { No one universal algorithm; scoring can be arbitrary; } \\
\text { responses to questions can be subjective. }\end{array}$ \\
\hline $\begin{array}{c}\text { Probabilistic or Bayesian approaches: Probability for } \\
\text { causality calculated from prior knowledge \& need the } \\
\text { specific findings in a case. }\end{array}$ & $\begin{array}{c}\text { Overcome the numerous limitations associated with } \\
\text { expert judgement \& algorithms; valid and internally } \\
\text { consistent assessment. }\end{array}$ & $\begin{array}{c}\text { Poor specificity; complex calculations; requires more } \\
\text { time and more expertise. }\end{array}$ \\
\hline
\end{tabular}

Table 3: Methods of ADR evaluation.

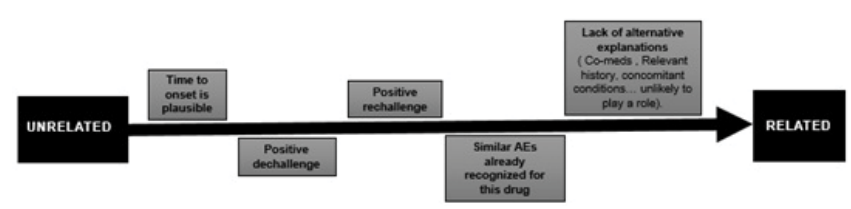

Figure 2: Method of global introspection (Clinical judgment).

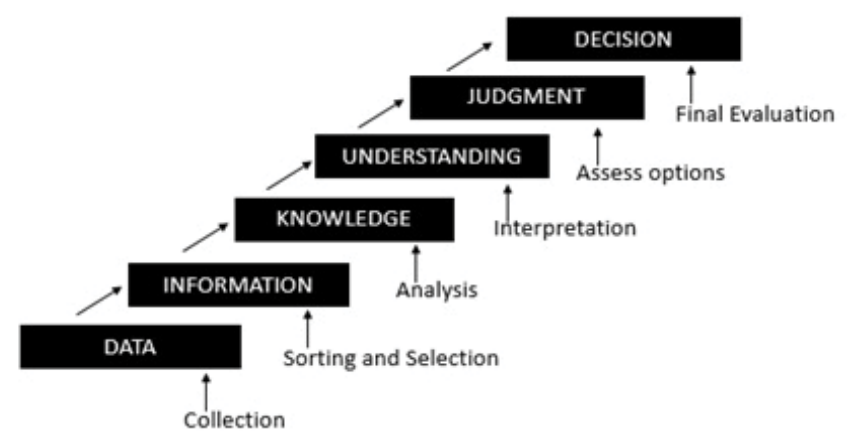

Figure 3: Decision making for the global introspection method.

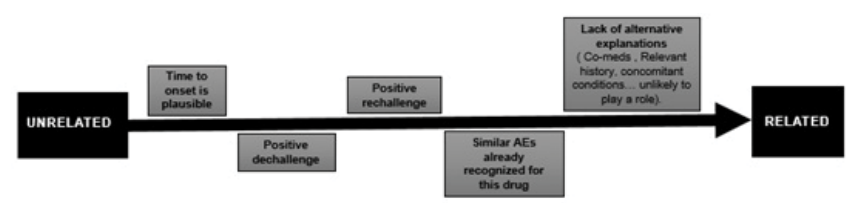

Figure 4: Baseline for an ADR evaluation.

objectivity on the diagnosis, it is useless to identify the unknown reactions and does not provide criteria for individual judgments or data for the reproducibility of the evaluation.

\section{The Kramer's Scale}

Generates disagreement in the judgment of etiological alternatives.

\section{The Naranjo's Algorithm}

It is the most used algorithm, although it is less practical, because it requires greater pharmacological knowledge on the part of the evaluator and/or interest in finding the necessary information. But again, the greatest source of disagreement is the assessment of alternative causes.

\section{The Begaud's Algorithm}

Although it has high specificity, it has very low sensitivity.

A study was done comparing the results obtained with the Adverse Reactions Probability Scale (ARPE-Naranjo's Algorithm) with those obtained with the Adverse Event Scoring System (AESS-Kramer's scale) in which 63 ADRs were evaluated by two observers, using ARPE and AESS for one year. The cases were ordered in a random sequence. The results suggest that although AESS is somewhat more complex than ARPE, both are equally reliable and give very similar results in relation to the likelihood of ADRs (Busto et al., 1982).

\section{Discussion}

Positive impact on quality of healthcare services can be significantly observed by reduction of ADRs in patients and one of the most important key factors in reducing the incidence of ADRs is undoubtedly its precise diagnosis. The major rationale for the utilization of algorithms is to augment inter- and intra-rater agreement and it should be highlighted that, they are neither designed nor intended to replace medical diagnosis. In algorithms, presence of some inappropriate questions leads to responses categorized as unidentified, which concludes in the lack of sensitivity with underestimation of probability of an ADR. Moreover, almost all the algorithms of causality assessment tools have shown lack of consistency and reproducibility of causality and therefore their reliability always remains uncertain. It is also necessary to observe the inapplicability of the algorithms in cases of clinical studies. The hallmark of algorithms is that, they have basic and intrinsic intricacies in establishing sensitivity and specificity of causality tools and therefore an algorithm that works in one Pharmacovigilance dataset may not work in a different dataset. Consequently, in spite of rigorous attempts since last four decades across the globe, there is still non-availability of universally accepted algorithm, as a gold standard. The current state of art in the diagnosis of ADRs is empirically based, expert judgment is typically based on the decisive factor on which algorithms are based, nevertheless in imprecise manner. The probabilistic methods use the similar principle; however, connect probabilities to each measure. Such approaches are quite sceptical and liable to generate cloudy causation results. In view of revamping the monitoring of drug safety and improvisation of Pharmacovigilance, innovative techniques are required for the precise diagnosis of ADRs.

\section{Conclusion}

In this way, it is possible to see that the applicability of the algorithms has several and different limitations.

It should be emphasized a subjective value, based on clinical experience, that cannot be contemplated in the algorithms and that contributes enormously to the establishment of the causal relationship. However, difficulties in standardization of evaluation are encountered when using the clinical judgment method. The training and the different medical point of view from each evaluator, based also on the local culture, can make the evaluation more conclusive, but not necessarily $100 \%$ coherent with what everyone thinks. Therefore, still there is a need to develop a high-quality assessment tool which can meticulously establish suitable diagnostic criteria for ADRs with universal acceptance to improvise the fundamental aspect of drug safety and evades the impending ADRs. 


\section{References}

1. Naranjo CA, Busto U, Sellers EM, Sandor P, Ruiz I, et al. (1981) A method for estimating the probability of adverse drug reactions. Clin Pharmacol Ther 30 239-245

2. Busto U, Naranjo CA, Sellers EM (1982) Comparison of two recently published algorithms for assessing the probability of adverse drug reactions. $\mathrm{Br} \mathrm{J}$ Clin Pharmacol 13: 223-227.

3. Capella D, Laporte JR (1989) Mechanisms of production and clinical diagnosis of undesirable effects produced by medicines. In: Laporte JR, Tognoni G, Rozenfeld S (eds) Epidemiology of Medication. Sao Paulo-Rio de Janeiro: Hucitec-Abrasco. pp: 115-124.

4. Edwards IR, Aronson JK (2000) Adverse drug reactions: Definitions, diagnosis and management. Lancet 356: 1255-1259.
5. Gomes M, Reis A (2001) Pharmaceutical Sciences. An Approach in Hospital Pharmacy. 1st edn. Sao Paulo. pp: 125-146.

6. Gross FH, Inman WH (1977) Drug monitoring. New York: Academic Press.

7. Hutchinson TA, David AL (1989) Assessing methods for causality assessment of suspected adverse drug reactions. J Clin Epidemiol 42: 5-16.

8. Karch FE, Lasagna L (1977) Towards the operational identification of adverse drug reactions. Clin Pharmacol Ther 21: 247-254.

9. Lee PR, Herzstein J (1986) International drug regulation. Annu Rev Public Health 7: 217-235.

10. World Health Organization (2002) The Importance of pharmacovigilance: Safety monitoring of medicinal products. Geneva: World Health Organization. 